\title{
NOTES
}

On the Back Cover:

\section{A PREVIOUSLY UNRECORDED PHOTOGRAPH OF WHITMAN AT HIS MICKLE STREET HOME}

The previously unrecorded photograph of Whitman sitting in his rocking chair in his Mickle Street home in Camden, New Jersey, was recently added to the Kendall Reed Collection. Notes on the back of the photograph indicate it was originally part of the Frank J. and Harriet Sprague Collection of Whitman materials.

One of the most striking of the late photographs of Whitman, this one was likely taken by Frank P. Harned, the brother of Whitman's close friend and one of his literary executors Thomas Harned, who took another photograph in the same setting and probably in the same session, circa 1887 . The known Harned photograph is reprinted here next to the newly discovered one. Notice the covered window and curtain backdrop, as well as the identical positioning

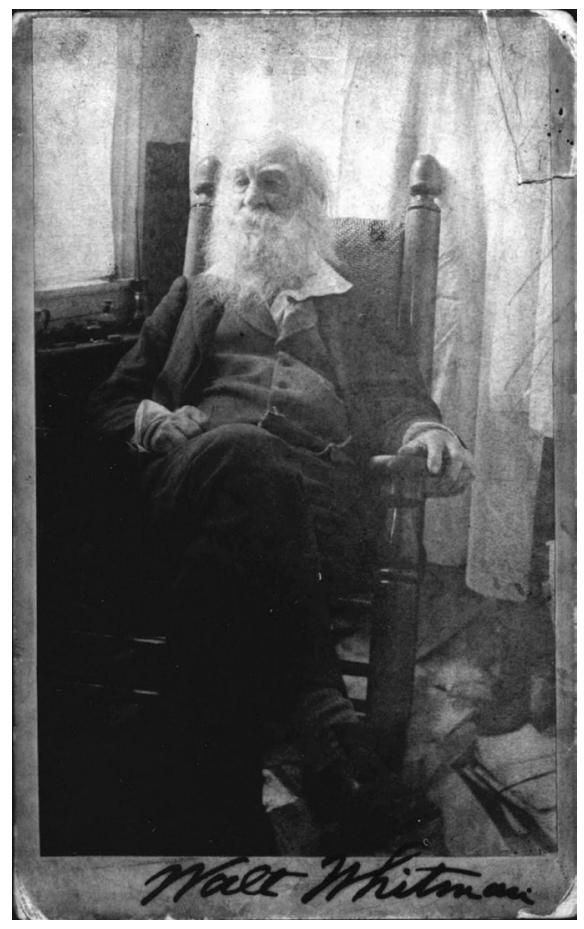

Figure 1

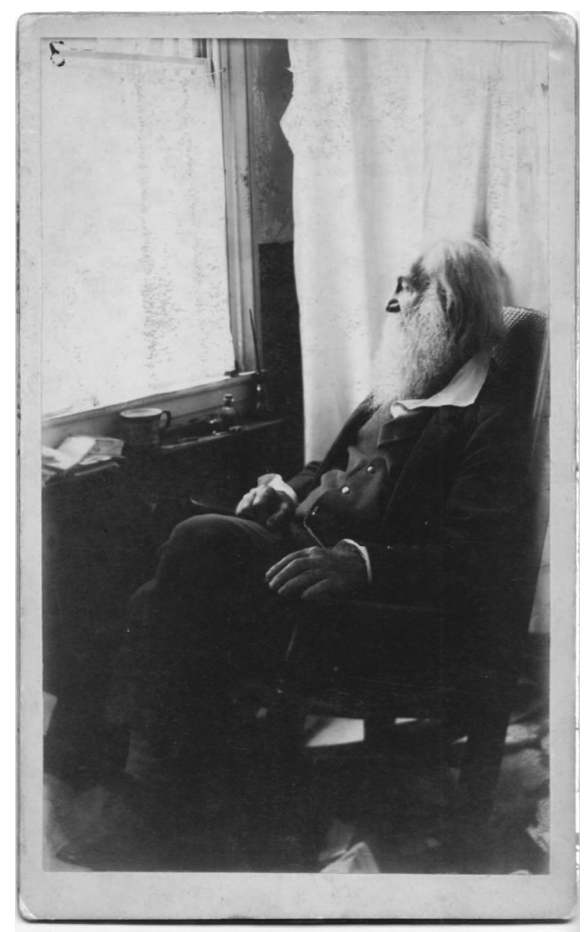

Figure 2 
of the same objects on the shelf below the window, where, in the new photo, we can see one of Whitman's omnipresent notebooks, along with his tea cup and his pen.

Whitman's only comment to Horace Traubel about Harned's photos indicated that he "has not seemed to like Frank Harned's pictures." When asked why, Whitman responded, "I don't know why—never do. I have feelings about things, nothing more." (With Walt Whitman in Camden, 1:420; available on The Walt Whitman Archive). Whitman may have on that occasion been talking about Frank Harned's attempts to photograph Sidney Morse's then-recently completed bust of Whitman, photos that Whitman found "weak, defective, futile," "totally a fizzle." (WWWC, 5:280-281).

Despite whatever reservations Whitman may have had about Frank Harned as a photographer, this newly rediscovered image of Whitman is a powerful one-both in the intimacy of the domestic details (including the just visible clutter on the floor around his rocking chair) and in the majesty of the poet's head in a profile shot that anticipates the much more familiar late profile photos by Thomas Eakins and Samuel Murray taken the year before Whitman's death.

This photo will soon be available on The Walt Whitman Archive (whitmanarchive.org), where all other known photographs of Whitman are currently available. 